\title{
FEMALE BAMBOO BASKET WEAVERS - PAIN ANALYSIS USING BODY MAP
}

\author{
M. AKSHATA ${ }^{1}$, D. RATNA KUMARI ${ }^{2} \&$ V. VIJAYA LAKSHMI ${ }^{3}$ \\ ${ }^{1}$ Student, Department of RMCS, College of Home Science, Saifabad, Hyderabad, Telangana, India \\ ${ }^{2}$ Professor, Department of RMCS, College of Home Science, Saifabad, Hyderabad, Telangana, India \\ ${ }^{3}$ Principle Scientist, AICRP-HSC, PG\& RC, PJTSAU, Hyderabad, Telangana, India
}

\begin{abstract}
The workload of female basket weavers was analyzed in this research study. Purposive random sampling method was used to select the respondents. A structured questionnaire and body map was used to determine the body pain and discomforts. The results revealed that most of the respondents experienced body pain in the neck, shoulder, upper arm, lower arm, wrist, fingers, ankle and toes. The frequency and intensity of pain varies from activity to activity performed by the weavers. Majority of the respondents experienced moderate pain in the shoulder, neck, upper arm, lower arm, elbow, toes, knees and ankle, irrespective of the activity. Severe pains in the wrist fingers and lower back, irrespective of the activity.
\end{abstract}

KEYWORDS: Bamboo Basket, Weaving, Female, Workload, Body Map \& Body Pain

Received: May 19, 2018; Accepted: Jun 09, 2018; Published: Jul 16, 2018; Paper Id.: IJESRAUG20183

\section{INTRODUCTION}

Basket weavers have been making a variety of handmade baskets from a wide array of grass for thousands of years in India. Basket weaving is considered as one of the works in the unorganized sector (Devi and Kiran2015). Das. et al,. (2018) stated that the prevalence of musculoskeletal symptoms among handicraft workers ranges between $38.5 \%-100 \%$, and the most affected body areas were the neck, back, knees and upper limbs. Pain is the first manifesting symptom of any WMSDs. Risk factors including working posture, daily working hours, repetitive and forceful movements, work experience, age, gender, working under stressful conditions was found to be highly associated with the occurrence of WMSDs.

Shoulder pain, upper back pain and wrist pain are the top three manifestations of musculoskeletal disorders prevalent among the rice keeper basketwork workers (Buranruket al., (2016) and also irrespective of age women basket weavers had low back pain (Parimalamet al., 2016). Numerous reports have been published on the occurrence of low back pain in different occupational groups and working conditions. Epidemiological studies on low back pain have shown clear relationships with heavy physical work, frequent bending and twisting, and lifting. The other parts of the body that experiences pain include knee joint, upper arms and lower arms.

Bamboo Basket weaving has been in focus since the 1990's where much of research work was done on the socio-economic conditions of basket weavers but very few studies have been conducted on the aspects of basket weaver's health and ergonomic problems. So, the present study was envisaged is to investigate the pain experienced and workload of female basket weavers. 


\section{METHODOLOGY}

\section{Research Design}

Experimental research design was used to study the sample of 30 female basket weavers in Hyderabad and Secunderabad city. Purposive sampling technique was adopted to select the samples. The Independent and dependent variables selected for the study are as follows.

\section{Dependent Variables}

- Body pain

\section{Independent Variables}

- $\quad$ Age of the respondent

- Years of experience

\section{Measurement Tools}

A structured questionnaire and body map was used to study the workload of female basket weavers.

\section{Statistical Analysis}

The data was analyzed by using frequencies and percentages. Correlation was calculated to find out the relation between independent variables and dependent variables to draw significant conclusions.

\section{RESULTS AND DISCUSSIONS}

The results related to the pain occurrence in different Body Parts on a Body Mapping. The results with relation to years of experience are discussed below and are displayed in Figure -1.

With relation to the years of experience, among the respondents who had around 5-10 years of work experience, around 16.66 per cent had pain in neck, lower back 16.66 per cent, shoulder 16.66 per cent, upper arm 6.66 per cent, lower arm 16.66 per cent, fingers/ wrist 13.33 per cent, lower leg 13.33 per cent, ankle 6.66 per cent, upper back 6.66 per cent and knee joint 6.66 per cent. Of the respondents with 10 - 15 years of work experience, around 10.00 per cent had pain in neck, shoulder 10.00 per cent, lower leg 10.00 per cent, lower back 6.66 per cent, upper arm 6.66 per cent, lower arm 6.66 per cent, fingers/ wrist 6.66 per cent, ankle 6.66 per cent, upper back 6.66 per cent and knee joint 6.66 per cent.

Twenty per cent of the respondents who had around 15 - 20 years of work experience, had pain in neck, lower back 20.00per cent, fingers/ wrist 20.00per cent, lower arm 20.00per cent, ankle 20.00per cent, upper arm 16.66per cent, shoulder 16.66per cent, upper back 16.66per cent, knee joint 16.66per cent, upper leg 16.66per cent and lower leg 16.66per cent. With relation to the years of experience, among the respondents who had above 20 years of work experience, around 50.00 per cent had pain in fingers/ wrist, lower back 50.00 per cent, knee joint 46.66 per cent, neck 46.66 per cent, shoulder 40.00 per cent, lower arm 40.00 per cent, lower leg 40.00 per cent, ankle 26.66 per cent, upper arm 16.6 percent, upper back 16.66 per cent, upper leg 16.66 per cent and as shown in the Figure 1. 


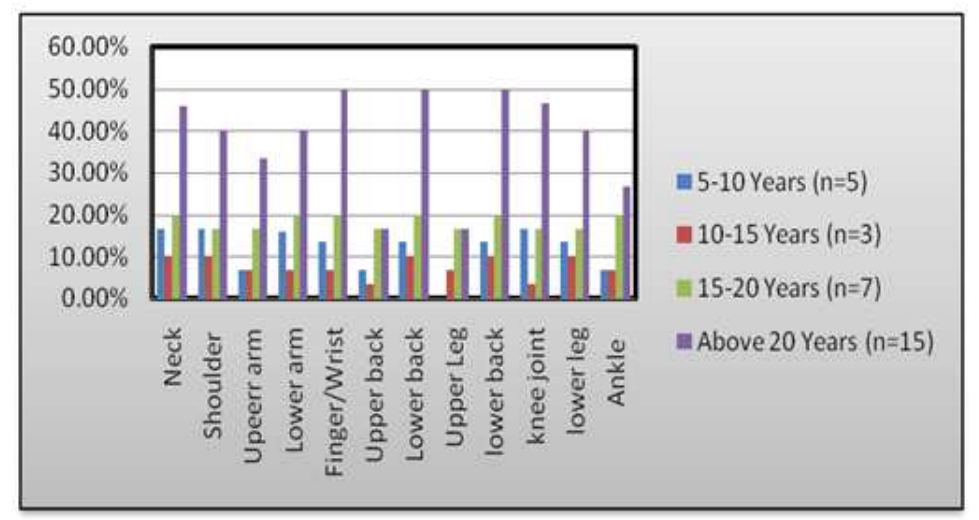

Figure 1: Body Parts and Occurance of Pain with Different Years of Experience

Table 1: Relationship between Independent Variables and Body Mapping

\begin{tabular}{|l|c|c|c|}
\hline & Age of respondent & Years of experience & Body Mapping \\
\hline Age of respondent & 1 & & \\
\hline Years of experience & $0.417789798^{*}$ & 1 & \\
\hline Body mapping & 0.248445619 & 0.304620047 & 1 \\
\hline
\end{tabular}

* Correlation is significant at the 0.05 level (2-tailed). $(\mathrm{p}<0.05)$

** Correlation is significant at the 0.01 level $(2$-tailed $) .(\mathrm{P}<0.01)$

The present study found that there was no significant correlation between Body map and age and years of experience (Table-1).

\section{Experience of Pain in Different Body Parts While Performing Different Activities}

The results regarding the experience of pain in different body parts of the respondents while performing different activities of basket weaving i. e. cutting, splitting, weaving the base, weaving the sides and finishing, the major activities of basket weaving work are shown in (Figure 2)

\section{Cutting Activity}

None of the respondents experienced pain in the head. Moderate pain experience in eyes 76.00 per cent, upper arm 70.00 per cent followed by knee 64.00 per cent, neck 54.00 per cent, lower back 52.00 per cent, ankle 46.00 per cent, toes 44.00 per cent, wrist 42.00 per cent, and Sever pain experience wrist 46.00 per cent and in the fingers 32.00 per cent, as seen in (Figure-2 a).

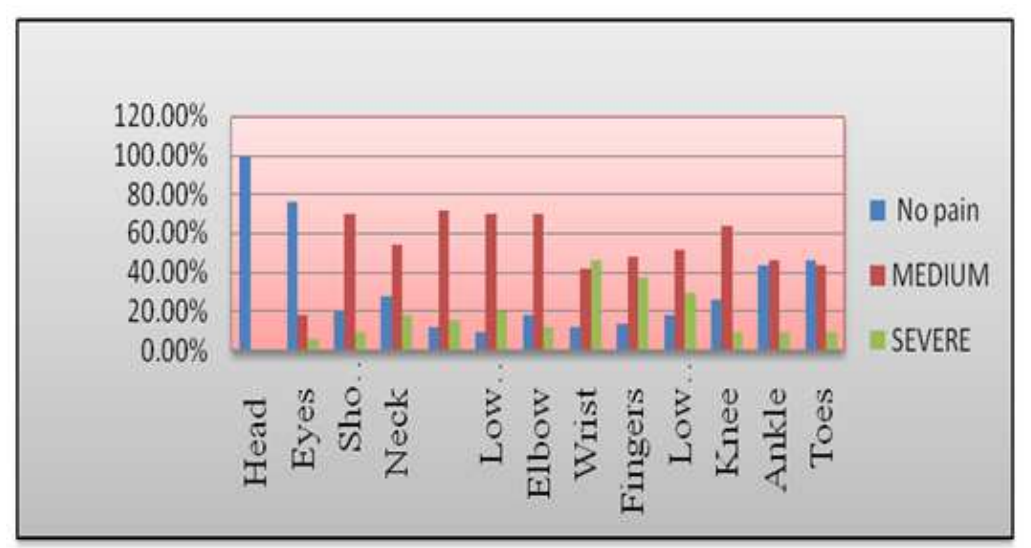

Figure 2 (a): Pain Realization in diities fferent Body Parts While Performing Cutting Activity 


\section{Splitting Activity}

Result showed that majority of the respondents experienced pain in eyes followed by toes and ankles. None of the respondents experienced pain in head. Moderate pain experience in upper arm 90.00per cent, followed by shoulder 74.00per cent, lower arm, elbow, knee 66.00 per cent each, neck 62.00 per cent, lower back 58.00 per cent and ankle 54.00 per cent. Fifty-two percent of respondent's experienced severe pain in wrist and forty- two percent of respondents experienced severe pain in fingers, as seen in (Figure-2 b).

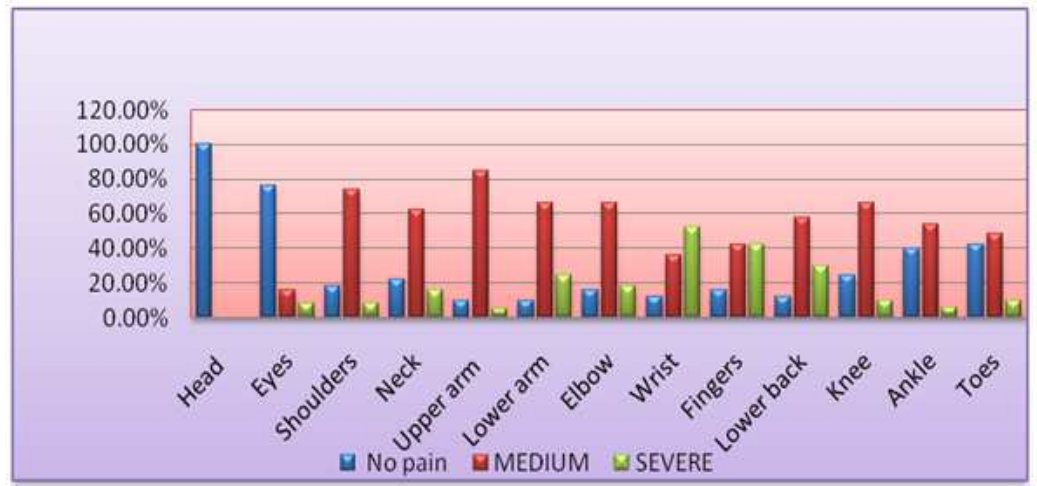

Figure 2 (b): Pain Realization in diities fferent Body Parts While Performing Splitting Activity

\section{Weaving the Base}

Results revealed base three fourth of respondents experienced pain in eyes and none of the respondents experienced pain in the head. Seventy four per cent of respondents experienced moderate pain in upper arm and lower arm followed by shoulder, knee, and neck. Fifty two percent of respondents experienced, severe pain in the wrist and forty two percent of respondents experienced severe pain in lower back, as seen in (Figure-2 c).

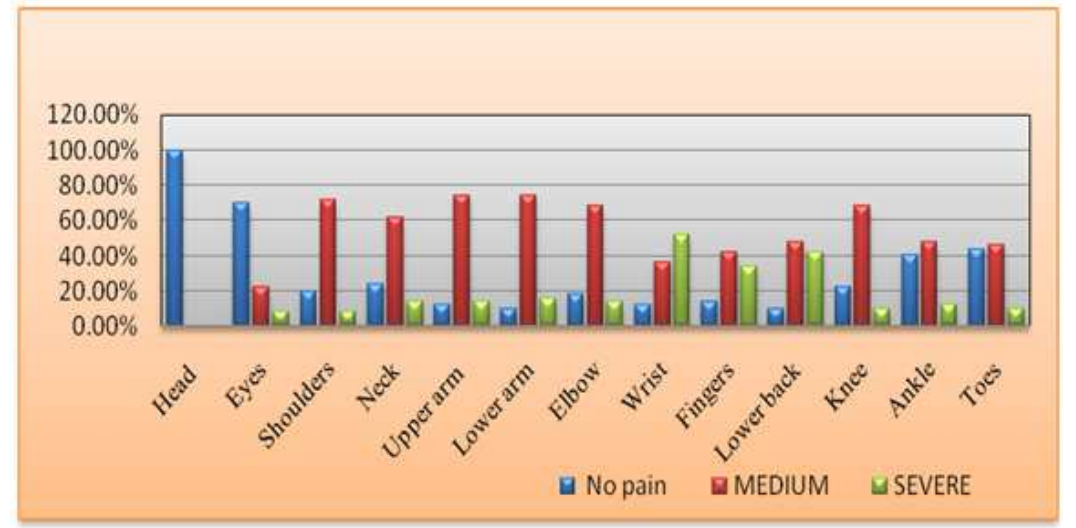

Figure 2 (c): Pain Realization in diities fferent Body Parts While Performing Weaving Base Activity

\section{Weaving the Sides}

Result showed that seventy-two percent of respondents experienced pain in eyes and none of the respondents experienced pain in the head. Moderate pain experienced in lower arm 74.00 per cent, followed by upper arm 70.00 per cent, shoulder 64.00 per cent and neck 62.00 per cent and lower back52.00 per cent. Sever pain experienced in wrist 60.00 per cent followed by in fingers 52.00 per cent, as seen in (Figure $2 \mathrm{~d}$ ). 


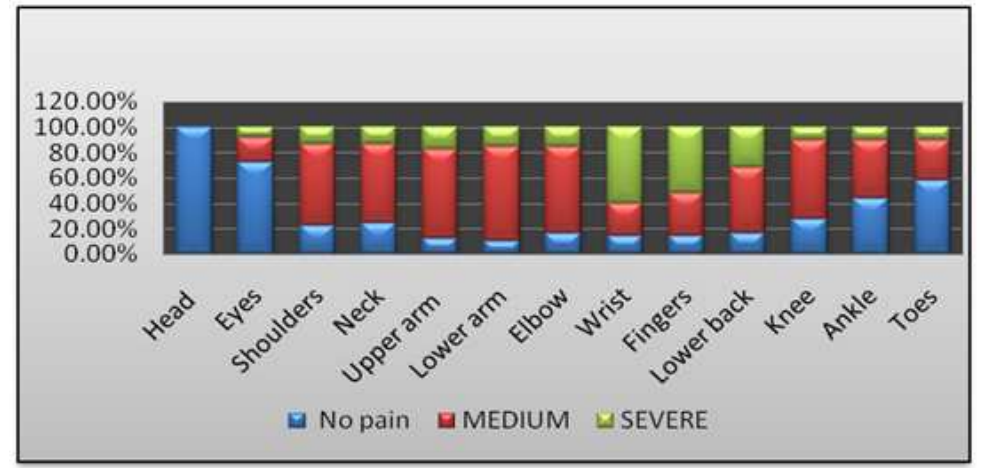

Figure 2 (d): Pain Realization in diities fferent Body Parts While Performing Weaving the Side Wall

\section{Finishing Activity}

The majority of the respondents experienced pain in eyes and none of the respondents experienced pain in the head. Moderate pain experience in upper arm 72.00 per cent, followed by lower arm 70.00 per cent, elbow 66.00 per cent, knee and shoulder 64.00 per cent and neck 60.00 per cent Sever pain experience wrist 62.00 per cent followed by fingers 46.00 per cent and lower back 30.00 per cent, as seen in (Figure-2 E).

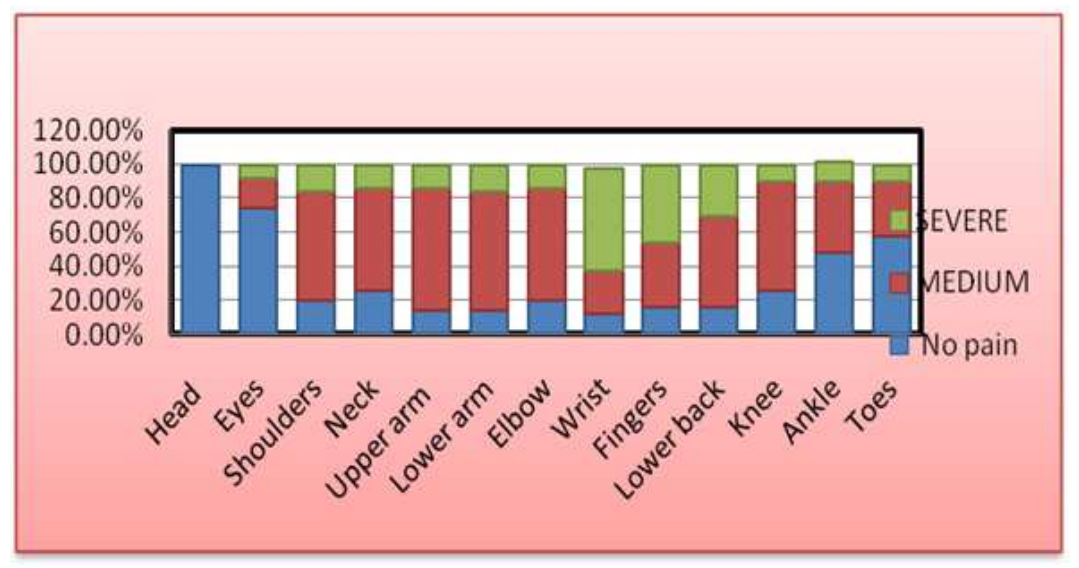

Figure 2 (e): Pain Realization in diities fferent Body Parts While Performing finishing

It can be seen from the results majority of the respondents of moderate pain in the shoulder, neck, upper arm, lower arm, elbow, toes, knees and ankle; severe pains in the wrist fingers and lower back, irrespective of the activity. None of the respondents had a pain in the head, irrespective of the activity. (Figure 2)

\section{CONCLUSIONS}

Irrespective of the age group, most of the respondents had pain in neck, eye, upper arm, lower arm, shoulder, wrist, finger, lower back pain, and ankle while performing different basket weaving activities and basket weaving work involves continuous sitting and continuous working with hands, most of the respondents faced severe pain in the wrist, fingers and lower back.

The manifestation of pain as expressed by the respondents was due to the use of tools and posture adopted. The respondents were not positive to the possibility of changing their posture from sitting to standing or sitting on a stool and placing the basket to be weaved on an elevated platform. 
As there is little possibility of changing the posture and method of weaving baskets two modifications are suggested. Number one, the development of a low stool with back ans armrest and secondly designing of lightweight hand tools like knife and hacksaw which can help in reducing the working load to overcome the body pain and musculoskeletal disorders and enhance the work process for increasing their socio-economic status and income.

\section{REFERENCES}

1. Buranruk, O., Eungpinithpong, W., Puntumetakul, R., Wongwilairat, K. 2016. Musculoskeletal

2. $\quad$ Disorders Among Rice Keeper Basketwork Workers. Advances in Physical Ergonomics and Human Factors pp 83-91

3. Devi. K and Kiran, U. V. 2015. Work related musculoskeletal disorders among workers in unorganized sector. International Journal of Technical Research and Applications. 3: 225-229.

4. Das, D., Kumar, A and Sharma, M. 2018. A Systematic Review of Work-related Musculoskeletal Disorders among Handicraft Workers. International Journal of Occupational Safety and Ergonomics. 31: 1-16.

5. Sreenivasulu, Sane, and K. Yogesh. "Compressive Properties of Polycarbonate Toughened Epoxy-Bamboo Fiber Composites."

6. Parimalam, P and Balakamakshi, K. 2016. Musculoskeletal problems of women bamboo workers in Madurai, India. https://www.researchgate.net/publication/265430040 